\section{Atmospheres and other fluids}

Atmospheric Thermodynamics. (Geophysics and Astrophysics Monographs: an International Series of Fundamental Textbooks, Vol. 6.) By J. V. Iribarne and W. L. Godson. Pp. $\mathrm{x}+222$. (Reidel: Dordrecht and Boston, Massachusetts, 1973.) n.p. Advanced Fluid Mechanics: An Introduction. By A. J. Raudkivi and R. A. Callander. Pp. xii +325. (Edward Arnold: London, July 1975.) Boards £12.00; paper $£ 5.00$.

THE book by Iribarne and Godson, which is based upon undergraduate lecture courses given by the authors, will be welcomed by students of the atmospheric sciences. It is one of the few textbooks in meteorology to deal exclusively with atmospheric thermodynamics and doubtless it will soon become deservedly established as a standard recommended text. The authors asume some knowledge of basic thermodynamics but devote the first four chapters of the book to a review of the fundamental relationships and concepts in the subject. There is some reference to the applicability of these relationships to meteorological problems in the introductory chapters but that aspect is more strongly emphasised in the latter half of the book. Strictly thermodynamic atmospheric processes are discussed at length (fog formation, cloud physics, precipitation, and so on) but sections are also included in which the importance of atmospheric dynamics and radiative processes is emphasised.

Throughout the text one is impressed by the concise and systematic treatment of the subject. Problems are given at the end of each chapter, the diagrams are informative and the book as a whole is well written and well presented. It has a good balance between basic thermodynamics and meteorological applications and will be useful to students and reseach workers alike.

With students of engineering particularly in mind. Raudkivi and Callander in their book have attempted to produce a work filling a gap which they feel exists between 'elementary' and 'advanced' texts on fluid mechanics. Claiming that the latter have been written almost exclusively by applied mathematicians (Batchelor's "Introduction to Fluid Dynamics" is cited as one example) their nrimary requirement has been to make the mathematical background simpler and more accessible to students already familiar with elementary fluid mechanics. It will be difficult for the reader to discern any significant improvement upon Batchelor's book in this regard. if indeed such a comparison is appro- priate. A lengthy section on turbulent flows is included, for example, as is an interesting survey of diffusion and dispersion. The remainder of the text is taken up with chapters on potential flow theory, boundary layers (surprisingly appearing after the section on turbulent flow) and fundamental relationships.

The latter contains much information (rheological models, tides) not usually included in such a section and, as with the rest of the book, it is well written and well presented. Particularly attractive features of the book are the inclusion of experimental data to complement theoretical ideas, and a generous supply of worked examples.

Of necessity, the authors have had to be selective in their choice of topics but they have produced a book which will be of interest to workers in several branches of fluid mechanics.

$$
\text { P. A. Davies }
$$

\section{Basic astronomy}

Astronomy Today. By Fred Hoyle. Pp. 179. (Heinemann Educational: London, October 1975.) $£ 4.50$.

Astronomy Today is a straightforward basic astronomy text, of the kind which many astronomers could write but which inevitably will reach a larger audience than most through the magic of the author's name. The book is lavishly illustrated and the text is clear, informative and readable. But given its title this is a disappointing book, which describes the Solar System in five chapters, the stars and life in the Universe in one each, and devotes the last chapter to Galaxies and the Universe, presenting a lucid exposition of Hoyle's picture of the redshift as indicating a Universe in which the mass of atoms increases with time.

This presentation of unorthodox ideas in such a way at the end of what is otherwise an orthodox book published in an educational series is curious, to say the least, and it seems that the UK publishers must take the blame for this, since the US edition of the book bears the much more apposite title Highlights in Astronomy (Freeman, 1975). The implication that this theory is as well established and broadly accepted as such fundamentals as the causes of seasons and eclipses is most ill-judged in the context of an educational text for young people. And the publishers are further guilty of misjudgement in describing the book on the cover as "ranging from the geological history of the Earth to the latest discoveries about neutron stars and black holes". Black holes are mentioned (once), but only in passing, and there is no mention at all of the state of the art in X-ray astronomy today, the field in which most of the latest discoveries about black holes and neutron starts have been made.

This is a fine description of "the Solar System today", but in no way is the book representative of the exciting recent advances in high energy astrophysics that the cover and the author's name lead us to expect. It is doubly ironic that not only is Hoyle ideally equipped to write the book we are led to expect, but also that his exposition of novel cosmological ideas would sit far more happily in such a volume.

John Gribbin

\section{Riboflavin}

Riboflavin. Edited by Richard $\mathbf{S}$. Rivlin. Pp. xiii +433. (Plenum : New York and London, 1975.) \$46.90.

THIS book comprises a collection of review articles by different workers on the chemistry, physiology and metabolism of riboflavin and the effects of riboflavin deficiency principally in man and rat. Hormonal regulation of riboflavin metabolism, studies on analogues and antagonists and a uscful section on methods of assay are well described. Of special interest are the sections on the teratological consequences of riboflavin deficiency and the effect of deficiency on the growth of neoplastic tissue. Editorially the texts have been well cross-referenced and repetition has been minimised without adversely affecting content and readability.

Some abbreviations are used without a preceding definition-M: $\mathbf{E}$ ratio and $\mathrm{PAH}$-and inconsistencies occur with others-for example, nicotinamide adenine dinucleotide, NAD (p162), DPN (p308). One section presents arguments for the further enrichment of bread as a means of improving riboflavin status in the US but alternative methods are hardly discussed.

The most serious omission is the lack of adequate detail and discussion on obtaining riboflavin-deficient rats. Chapter 10 mentions briefly (7 lines) the many factors that can influence the deficient state (p305) but without any explanation; and, for the diet used by the author, the reader is referred to a 'recent' reference 1951! This is presumably a mistake, as the diet to which one is referred in no way satisfies the 'scvere criteria of deficiency' which the writer considers necessary.

In general, however, the book is well referenced and will providc a valuable and timcly addition to the bookshelves of medical schools and institutions of nutrition and pharmacy. David I. Thurnham 